John Bartholomew, MD

Department of Cardiovascular Medicine,

Heart, Vascular, and Thoracic Institute,

Cleveland Clinic

\section{G. Jay Bishop, MD}

Department of Cardiovascular Medicine,

Heart, Vascular, and Thoracic Institute,

Cleveland Clinic

\title{
New treatments for peripheral artery disease
}

\section{ABSTRACT}

The stenosis or occlusion of extremities defining peripheral artery disease (PAD) is a risk factor for adverse cardiovascular events and adverse limb events including amputation. PAD is common, can occur without symptoms or with claudication, and is easily diagnosed. Proper diagnosis and adherence to guideline-directed therapy can reduce the morbidity and potential mortality associated with PAD.

\section{KEY POINTS}

PAD is stenosis or occlusion of the upper or lower extremities caused by atherosclerotic plaque.

PAD is common, often overlooked because it is frequently asymptomatic, but easily diagnosed by obtaining an ankle-brachial index.

Management and medical therapies for PAD include lifestyle measures, optimal blood pressure and cholesterol control, antithrombotic agents to manage the risk of thrombotic events, and claudication therapy.
The authors reported no financial interests or relationships that pose a potential conflict of interest with this article.

This article is based on Dr. Bartholomew's presentation at the Sones/Favaloro Scientific Program, "Multidisciplinary Management of Acute and Chronic Conditions: Yielding Exceptional Outcomes," held in Cleveland, $\mathrm{OH}$, November 8, 2019. The article was drafted by Cleveland Clinic Journal of Medicine and was then reviewed, revised, and approved by Dr. Bartholomew.

doi:10.3949/ccjm.87.s1.03

\section{INTRODUCTION}

Peripheral artery disease (PAD) is characterized by stenosis or occlusion of the arteries of the upper or lower limbs due to atherosclerotic plaque in the vessel walls. ${ }^{1}$ PAD is common but often overlooked. A public awareness survey found $74 \%$ of respondents $(\mathrm{N}=2,501)$ were not aware of PAD. ${ }^{2}$ Unfortunately, many physicians also lack awareness of PAD or fail to consider it when evaluating patients.

PAD is easily diagnosed in any office setting by obtaining an ankle-brachial index, which is the ratio calculated by the measured lower extremity (ankle) systolic pressure divided by the brachial artery (arm) systolic pressure. ${ }^{3}$ An ankle-brachial index of 0.91 to 1.4 is normal, 0.90 or less is diagnostic for PAD, and less than 0.40 is diagnostic for severe PAD. Patients may experience leg pain (claudication), rest pain, or leg ulcerations. The ankle-brachial index is $95 \%$ sensitive and $99 \%$ specific for PAD. ${ }^{3}$ With greater awareness and screening for PAD, significant patient morbidity can be avoided.

\section{EPIDEMIOLOGY AND PATHOPHYSIOLOGY}

Over 200 million people worldwide have PAD and it occurs in men and women equally. The prevalence of PAD increases with age occurring in about $30 \%$ of people over 70 and in people 50 to 69 with diabetes or those who smoke. ${ }^{4}$ Both mortality and disability from PAD have increased over the last several decades. Patients with PAD are at high risk for major adverse cardiovascular events and major adverse limb events, the most dreaded complication being amputation.

\section{SIGN AND SYMPTOMS}

Failure to recognize PAD is largely due to the absence of symptoms. In the ambulatory setting, about $50 \%$ of individuals with PAD have no leg symptoms whatsoever. ${ }^{5}$ Only about $15 \%$ of those with PAD have typical claudication, $30 \%$ have atypical limb symptoms, and about $3 \%$ have critical limb ischemia.

The 5 -year outcome for patients with PAD includes stable claudication in $70 \%$ to $80 \%$ of patients; $10 \%$ to $20 \%$ will require lower extremity revascularization, 
TABLE 1

Natural history of peripheral artery disease

\begin{tabular}{lcc}
\hline Symptoms at diagnosis in patients with PAD & Patients (\%) & 5-Year outcomes \\
\hline Asymptomatic & $20-50$ & Major adverse limb events \\
Atypical leg discomfort & $40-50$ & Stable claudication: $70 \%-80 \%$ \\
Claudication & $10-30$ & Lower extremity revascularization: $10 \%-20 \%$ \\
& & Critical limb ischemia: $1 \%-2 \%$ \\
& & Major adverse cardiovascular events \\
& & Myocardial infarction/stroke: $20 \%$ \\
Critical limb ischemia & & Death: $15 \%-30 \%$
\end{tabular}

Source: Data from reference 6

and about $1 \%$ to $2 \%$ will go on to have chronic limb ischemias (Table 1). ${ }^{6}$ Amputation rates are as high as $25 \%$ in patients with chronic limb ischemia. It is important to note that for patients with PAD, 20\% will have a myocardial infarction or stroke, and death can occur in $15 \%$ to $30 \%$ over a 5 -year period. As these data make clear, PAD is not a benign condition.

\section{MEDICAL THERAPIES AND MANAGEMENT}

As stated, PAD is routinely underdiagnosed but even with proper diagnosis, patients with PAD are less frequently treated with guideline-directed therapies compared with patients with coronary artery disease. ${ }^{4}$ Medical therapies for, and the management of PAD revolve around preventing myocardial infarction, stroke, and death; improving function and quality of life; and protecting the feet to avoid and prevent amputation.

\section{Diet, exercise, tobacco cessation}

Patients with PAD should be counseled about maintaining a healthy diet, exercise, and complete cessation of tobacco use. Recommended exercise programs for patients with PAD have been established and are covered services for older patients by US Centers for Medicare \& Medicaid Services. ${ }^{7}$ A 12 -week supervised treadmill exercise program consists of 3 weekly sessions that begin at 15 minutes and increase to 45 to 50 minutes a session. A home-based walking exercise program or a supervised ergometry exercise program are also recommended and may be better suited to some patients.

\section{Medical therapy}

In addition to lifestyle measures, medical therapies for PAD should be employed to:

- Optimize blood pressure preferably using an angiotensin-converting-enzyme inhibitor

- Lower and maintain low-density lipoprotein cholesterol (LDL-C) to less than $70 \mathrm{mg} / \mathrm{dL}$ using a statin, ezetimibe, or a proprotein convertase subtilisin-kexin 9 inhibitor or combination.

- Manage risk of thrombotic events with antithrombotic agents such as aspirin, clopidogrel, ticagrelor, vorapaxar, and rivaroxaban

- Treat claudication pain in the extremities with cilostazol if no heart failure.

Several major clinical trials have evaluated antithrombotic agents in patients with PAD, especially symptomatic PAD (Table 2). ${ }^{8-25}$

Among these trials, Cardiovascular Outcomes for People Using Anticoagulation Strategies (COMPASS) evaluated cardiovascular outcomes in 27,395 patients including 27\% with PAD. ${ }^{20}$ Patients received 2.5 $\mathrm{mg}$ rivaroxaban twice daily plus $100 \mathrm{mg}$ aspirin, or 5 $\mathrm{mg}$ rivaroxaban twice daily, or $100 \mathrm{mg}$ aspirin daily. The cardiovascular outcomes in patients with stable atherosclerotic vascular disease were more favorable in the rivaroxaban-plus-aspirin cohort (hazard ratio $=0.76 ; 95 \%$ confidence interval $[\mathrm{CI}]$ 0.66-0.86; $P=.001)$ compared with the rivaroxaban-alone cohort (hazard ratio $=0.90 ; 95 \%$ CI 0.79-1.03; $P=.12$ ), but more major bleeding events occurred in patients on rivaroxaban plus aspirin $(3.1 \%)$ compared with rivaroxaban alone $(1.9 \%)$. The secondary composite outcome of ischemic stroke, myocardial 
TABLE 2

Clinical trials of antithrombotic therapy for peripheral artery disease (PAD)

\begin{tabular}{|c|c|c|}
\hline & Therapy & Trial, date (agent) \\
\hline \multirow[t]{4}{*}{ Symptomatic PAD } & Single agent & $\begin{array}{l}\text { CAPRIE } 1996 \text { (clopidogrel vs placebo) }^{9} \\
\text { CLIPS } 2007 \text { (ASA vs placebo) } \\
\text { EUCLID } 2016{\text { (ticagrelor vs clopidogrel) })^{11}}^{10}\end{array}$ \\
\hline & Dual antiplatelet & $\begin{array}{l}\text { CHARISMA } 2009 \text { (clopidogrel + ASA vs ASA) })^{12} \\
\text { PLATO } 2015 \text { (ticagrelor + ASA vs clopidogrel + ASA) }{ }^{13} \\
\text { PEGASUS-TIMI } 542016 \text { (ticagrelor + ASA vs ASA) } \\
\text { PRODIGY } 2016 \text { (clopidogrel + ASA for } 24 \mathrm{M} \text { vs } 6 \mathrm{M})^{15} \\
\text { DAPT } 2017 \text { (P2Y12 inhibitor + ASA for 30M vs } 12 \mathrm{M})^{16}\end{array}$ \\
\hline & PAR-1 antagonist & $\begin{array}{l}\text { TRA2 P-TIMI } 502013 \text { (vorapaxar vs placebo) })^{17} \\
\text { TRACER } 2014 \text { (vorapaxar vs placebo) }{ }^{18}\end{array}$ \\
\hline & Anticoagulation & $\begin{array}{l}\text { WAVE } 2007 \text { (warfarin + antiplatelet vs antiplatelet) } \\
\text { COMPASS } 2017 \text { (rivaroxaban + ASA vs ASA) }{ }^{10}\end{array}$ \\
\hline Asymptomatic PAD & & $\begin{array}{l}\text { POPADAD } 2008 \text { (ASA vs placebo) })^{21} \\
\text { AAA } 2010 \text { (ASA vs placebo) }{ }^{22}\end{array}$ \\
\hline Revascularization for PAD & $\begin{array}{l}\text { Surgical } \\
\text { Endovascular }\end{array}$ & $\begin{array}{l}\text { Dutch BOA } 2000 \text { (anticoagulation vs ASA) }^{23} \\
\text { CASPAR } 2010 \text { (clopidogrel + ASA vs ASA) } \\
\text { MIRROR } 2012 \text { (clopidogrel + ASA vs placebo) }\end{array}$ \\
\hline
\end{tabular}

AAA = Aspirin for Asymptomatic Atherosclerosis; ASA = acetylsalicylic acid; BOA = Bypass Oral anticoagulants or Aspirin; CAPRIE = Clopidogrel Versus Aspirin in Patients at Risk of Ischaemic Events; CASPAR = Clopidogrel and Acetylsalicylic Acid in Bypass Surgery for Peripheral Arterial Disease; CHARISMA = Clopidogrel for High Atherothrombotic Risk and Ischemic Stabilization, Management, and Avoidance; CLIPS = Critical Leg Ischaemia Prevention Study; COMPASS = Cardiovascular Outcomes for People Using Anticoagulation Strategies; DAPT = dual antiplatelet therapy; EUCLID = Examining Use of Ticagrelor in Peripheral Artery Disease; M = months; MIRROR = Management of Peripheral Arterial Interventions With Mono or Dual Antiplatelet Therapy; PAR = protease-activated receptor; PEGASUS-TIMI 54 = Prevention of Cardiovascular Events in Patients With Prior Heart Attack Using Ticagrelor Compared to Placebo on a Background of Aspirin-Thrombolysis In Myocardial Infarction 54; PLATO = Study of Platelet Inhibition and Patient Outcomes; POPADAD = Prevention of Progression of Arterial Disease and Diabetes; PRODIGY = Prolonging Dual Antiplatelet Treatment After Grading Stent-Induced Intimal Hyperplasia Study; TRA2 P-TIMI 50 = Thrombin Receptor Antagonist in Secondary Prevention of Atherothrombotic Ischemic Events-Thrombolysis In Myocardial Infarction 50; TRACER = Thrombin Receptor Antagonist for Clinical Event Reduction in Acute Coronary Syndrome; WAVE = Warfarin Antiplatelet Vascular Evaluation

Source: Data from reference 8.

infarction, acute limb ischemia, or cardiovascular death also favored rivaroxaban-plus-aspirin therapy, with emphasis on screening for bleeding.

Figure 1 outlines a frequently used approach to antithrombotic therapy showing that all patients with symptomatic PAD should receive aspirin or clopidogrel or aspirin with rivaroxaban. ${ }^{8}$ In patients with asymptomatic PAD, aspirin should be considered especially if disease is present in another vascular bed.

\section{Summary of risk reduction therapy for patients with PAD}

The American College of Cardiology/American Heart Association 2016 guidelines on the management of patients with lower extremity PAD advise that reduction of risk for major adverse limb events should include healthy lifestyle modifications, tobacco cessation, achieving target blood pressure goals, glucose lowering therapy, LDL-C lowering using a statin or ezetimibe or a PCSK9 agent, and antiplatelet therapy. ${ }^{4,5}$
The Further Cardiovascular Outcomes Research With PCSK8 Inhibition in Subjects With Elevated Risk (FOURIER) trial provides insight into LDL-C levels and outcomes in patients with PAD. ${ }^{26}$ Of the 27,564 patients in the FOURIER trial, 13.2\% had PAD and by lowering LDL-C to a median of $31 \mathrm{mg} / \mathrm{dL}$ in patients with symptomatic PAD, major adverse cardiovascular events and major adverse limb events were reduced significantly. Evolocumab plus a statin to reduce LDL-C levels reduced the risk of major adverse limb events (ie, limb ischemia or loss of limb) by $42 \%$ in 2 study populations. ${ }^{26}$

For some patients with more advanced disease, aspirin together with rivaroxaban $(2.5 \mathrm{mg}$ twice daily) or ticagrelor (60 mg twice daily) or clopidogrel (75 mg once daily) with or without vorapaxar (2.08 mg once daily) is appropriate. Claudication therapy with cilostazol (100 mg twice daily) can be used for patients without heart failure. 


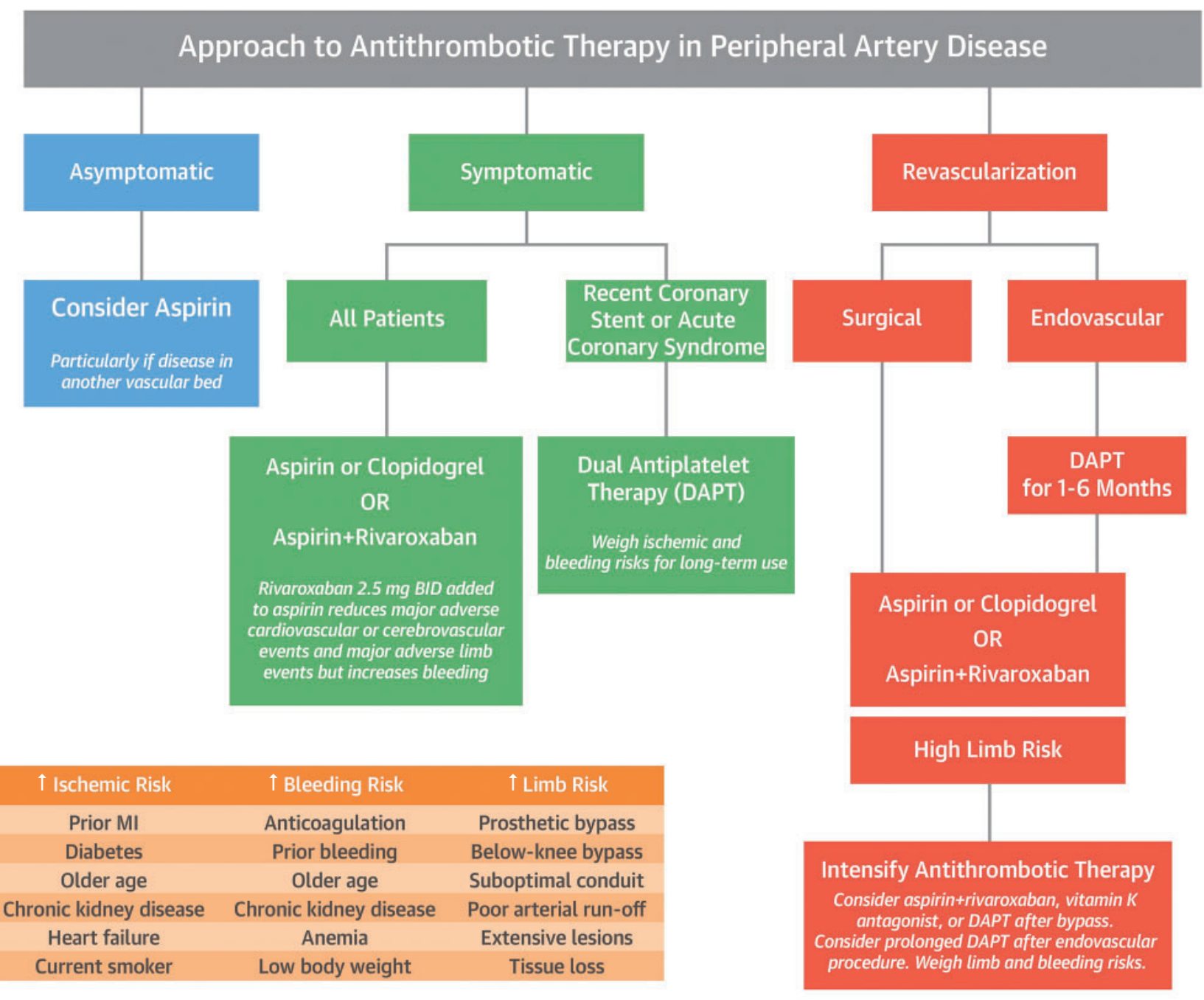

Figure 1. Therapeutic approach for patients with peripheral artery disease.

$\mathrm{BID}=2$ times per day; $\mathrm{MI}=$ myocardial infarction

Reprinted from Hussain MA, et al. Antithrombotic therapy for peripheral artery disease: recent advances. J Am Coll Cardiol 2018; 71(21):2450-2467. Copyright 2018, with permission from The American College of Cardiology Foundation.

\section{REFERENCES}

1. Hiatt WR, Goldstone J, Smith SC Jr, et al. Atherosclerotic Peripheral Vascular Disease Symposium II: nomenclature for vascular diseases [published correction appears in Circulation 2009; 119(25):e604]. Circulation 2008; 118(25):2826-2829. doi:10.1161/ CIRCULATIONAHA.108.191171

2. Hirsch AT, Murphy TP, Lovell MB, et al. Gaps in public knowledge of peripheral arterial disease: the first national PAD public awareness survey. Circulation 2007; 116(18):2086-2094. doi:10.1161/ CIRCULATIONAHA.107.725101

3. Criqui MH, Fronek A, Klauber MR, Barrett-Connor E, Gabriel S. The sensitivity, specificity, and predictive value of traditional clinical evaluation of peripheral arterial disease: results from noninvasive testing in a defined population. Circulation 1985; 71(3):516-522. doi:10.1161/01.cir.71.3.516

4. Gerhard-Herman MD, Gornik HL, Barrett C, et al. 2016 AHA/ACC Guideline on the Management of Patients With Lower Extremity Peripheral Artery Disease: Executive Summary: a report of the American College of Cardiology/American Heart Association Task
Force on Clinical Practice Guidelines [published correction appears in J Am Coll Cardiol 2017; 69(11):1520]. J Am Coll Cardiol 2017; 69(11):1465-1508. doi:10.1016/j.jacc.2016.11.008

5. Society for Vascular Medicine. Peripheral arterial disease (PAD). Society for Vascular Medicine webstite. http://myperipheralarterydisease. com/health-care-providers. Accessed March 5, 2020.

6. Hirsch AT, Haskal ZJ, Hertzer NR, et al. ACC/AHA 2005 Practice Guidelines for the management of patients with peripheral arterial disease (lower extremity, renal, mesenteric, and abdominal aortic): a collaborative report from the American Association for Vascular Surgery/Society for Vascular Surgery, Society for Cardiovascular Angiography and Interventions, Society for Vascular Medicine and Biology, Society of Interventional Radiology, and the ACC/AHA Task Force on Practice Guidelines (Writing Committee to Develop Guidelines for the Management of Patients With Peripheral Arterial Disease): endorsed by the American Association of Cardiovascular and Pulmonary Rehabilitation; National Heart, Lung, and Blood Institute; Society for Vascular Nursing; TransAtlantic Inter-Society Consensus; and Vascular Disease Foundation. Circulation 2006; 113(11):e463-e654. doi:10.1161/CIRCULATIONAHA.106.174526 
7. McDermott MM. Medical management of functional impairment in peripheral artery disease: a review. Prog Cardiovasc Dis 2018, 60(6):586-592. doi:10.1016/j.pcad.2018.03.007

8. Hussain MA, Al-Omran M, Creager MA, Anand SS, Verma S, Bhatt DL Antithrombotic therapy for peripheral artery disease: recent advances. J Am Coll Cardiol 2018; 71(21):2450-2467. doi:10.1016/j. jacc.2018.03.483

9. CAPRIE Steering Committee. A randomised, blinded, trial of clopidogrel versus aspirin in patients at risk of ischaemic events (CAPRIE). CAPRIE Steering Committee. Lancet 1996; 348(9038):1329-1339.

10. Critical Leg Ischaemia Prevention Study (CLIPS) Group; Catalano M, Born G, Peto R. Prevention of serious vascular events by aspirin amongst patients with peripheral arterial disease: randomized, double-blind trial. J Intern Med 2007; 261(3):276-284. doi:10.1111/j.1365-2796.2006.01763.x

11. Hiatt WR, Fowkes FGR, Heizer G, et al. Ticagrelor versus clopidogrel in symptomatic peripheral artery disease. N Engl J Med 2017; 376(1):32-40. doi:10.1056/NEJMoa1611688

12. Cacoub PP, Bhatt DL, Steg PG, Topol EJ, Creager MA; CHARISMA Investigators. Patients with peripheral arterial disease in the CHARISMA trial. Eur Heart J 2009; 30(2):192-201. doi:10.1093/ eurheartj/ehn534

13. Patel MR, Becker RC, Wojdyla DM, et al. Cardiovascular events in acute coronary syndrome patients with peripheral arterial disease treated with ticagrelor compared with clopidogrel: data from the PLATO Trial. Eur J Prev Cardiol 2015; 22(6):734-742. doi: $10.1177 / 2047487314533215$

14. Bhatt DL, Bonaca MP, Bansilal S, et al. Reduction in ischemic events with ticagrelor in diabetic patients with prior myocardial infarction in PEGASUS-TIMI 54. J Am Coll Cardiol 2016; 67(23):2732-2740. doi:10.1016/j.jacc.2016.03.529

15. Franzone A, Piccolo R, Gargiulo G, et al. Prolonged vs. short duration of dual antiplatelet therapy after percutaneous coronary intervention in patients with or without peripheral arterial disease: a subgroup analysis of the PRODIGY randomized clinical trial. JAMA Cardiol 2016; 1(7):795-803. doi:10.1001/jamacardio.2016.2811

16. Secemsky EA, Yeh RW, Kereiakes DJ, et al; Dual Antiplatelet Therapy Study Investigators. Extended duration dual antiplatelet therapy after coronary stenting among patients with peripheral arterial disease: a subanalysis of the dual antiplatelet therapy study. JACC Interv 2017; 10(9):942-954. doi:10.1016/j.jcin.2017.02.013

17. Bonaca MP, Scirica BM, Creager MA, et al. Vorapaxar in patients with peripheral artery disease: results from TRA2 ${ }^{\circ} \mathrm{P}$ TIMI 50. Circulation 2013; 127(14):1522-1529. doi:10.1161/ CIRCULATIONAHA.112.000679

18. Jones WS, Tricoci P, Huang Z, et al. Vorapaxar in patients with peripheral artery disease and acute coronary syndrome: insights from Thrombin Receptor Antagonist for Clinical Event Reduction in Acute Coronary Syndrome (TRACER). Am Heart J 2014; 168(4):588596. doi:10.1016/j.ahj.2014.06.017

19. Warfarin Antiplatelet Vascular Evaluation Trial Investigators; Anand S, Yusuf S, et al. Oral anticoagulant and antiplatelet therapy and peripheral arterial disease. N Engl J Med 2007; 357(3):217-227. doi:10.1056/NEJMoa065959

20. Eikelboom JW, Connolly SJ, Bosch J, et al; COMPASS Investigators. Rivaroxaban with or without aspirin in stable cardiovascular disease. N Engl J Med 2017; 377(14):1319-1330. doi:10.1056/ NEJMoa1709118

21. Belch J, MacCuish A, Campbell I, et al; Prevention of Progression of Arterial Disease and Diabetes Study Group, Diabetes Registry Group, and Royal College of Physicians Edinburgh. The prevention of progression of arterial disease and diabetes (POPADAD) trial: factorial randomised placebo controlled trial of aspirin and antioxidants in patients with diabetes and asymptomatic peripheral arterial disease. BMJ 2008; 337:a1840. doi:10.1136/bmj.a1840

22. Fowkes FGR, Price JF, Stewart MCW, et al; Aspirin for Asymptomatic Atherosclerosis Trialists. Aspirin for prevention of cardiovascular events in a general population screened for a low ankle brachial index: a randomized controlled trial. JAMA 2010; 303(9):841-848. doi:10.1001/jama.2010.221

23. Butch Bypass Oral Anticoagulants or Aspirin (BOA) Study Group. Efficacy of oral anticoagulants compared with aspirin after infrainguinal bypass surgery (The Dutch Bypass Oral Anticoagulants or Aspirin Study): a randomised trial [published correction appears in Lancet 2000; 355(9209):1104]. Lancet 2000; 355(9201):346-351.

24. Belch JJF, Dormandy J, CASPAR Writing Committee, et al. Results of the randomized, placebo-controlled clopidogrel and acetylsalicylic acid in bypass surgery for peripheral arterial disease (CASPAR) trial. J Vasc Surg 2010; 52(4):825-833. doi:10.1016/j.jvs.2010.04.027

25. Tepe G, Bantleon R, Brechtel K, et al. Management of peripheral arterial interventions with mono or dual antiplatelet therapy-the MIRROR study: a randomised and double-blinded clinical trial. Eur Radiol 2012; 22(9):1998-2006. doi:10.1007/s00330-012-2441-2

26. Bonaca MP, Nault P, Giugliano RP, et al. Low-density lipoprotein cholesterol lowering with evolocumab and outcomes in patients with peripheral artery disease: insights from the FOURIER Trial (Further Cardiovascular Outcomes Research With PCSK9 Inhibition in Subjects With Elevated Risk). Circulation 2018; 137(4):338-350. doi:10.1161/CIRCULATIONAHA.117.032235

Correspondence: John Bartholomew, MD, Department of Cardiovascular Medicine, Heart, Vascular, and Thoracic Insitute, ST20, Cleveland Clinic, 9500 Euclid Avenue, Cleveland, OH 44195; barthoj@ccf.org 